CORRECTION OPEN

\title{
Correction: Withdrawal from escalated cocaine self- administration impairs reversal learning by disrupting the effects of negative feedback on reward exploitation: a behavioral and computational analysis
}

Peter Zhukovsky, Mickael Puaud, Bianca Jupp, Júlia Sala-Bayo, Johan Alsiö, Jing Xia, Lydia Searle, Zoe Morris, Aryan Sabir, Chiara Giuliano, Barry J. Everitt, David Belin (D), Trevor W. Robbins and Jeffrey W. Dalley

Neuropsychopharmacology (2020) 45:714; https://doi.org/10.1038/s41386-019-0576-4

Correction to: Neuropsychopharmacology https://doi.org/10.1038/ s41386-019-0381-0, published online 6 April 2019.

Shortly after publication, the Authors noticed that two of the equations in the Methods section contained errors. The original Article contained a typographic error in Model-free Q-learning models 1 and 3 . The correct equations are as follows:

Model-free Q-learning: model 1

$P\left(c_{t}=L \mid Q_{t}(L), Q_{t}(R)\right)=\frac{\exp \left(Q_{t}(L) / \beta\right)}{\exp \left(Q_{t}(L) / \beta\right)+\exp \left(Q_{t}(R) / \beta\right)}$

Model-free Q-learning: model 3

$$
\begin{aligned}
P\left(c_{t}\right. & \left.=L \mid Q_{t}(L), Q_{t}(R), L_{t-1}, R_{t-1}\right) \\
& =\frac{\exp \left(Q_{t}(L) / \beta+\kappa * L_{t-1}\right)}{\exp \left(Q_{t}(L) / \beta+\kappa * L_{t-1}\right)+\exp \left(Q_{t}(R) / \beta+\kappa * R_{t-1}\right)}
\end{aligned}
$$

The correct equations were used for the data analyses performed in the original Article. The analyses, results and conclusions of the paper were not affected by the typographic error. This has now been corrected in both the PDF and HTML versions of the Article.

(c) (i)

Open Access This article is licensed under a Creative Commons Attribution 4.0 International License, which permits use, sharing, adaptation, distribution and reproduction in any medium or format, as long as you give appropriate credit to the original author(s) and the source, provide a link to the Creative Commons license, and indicate if changes were made. The images or other third party material in this article are included in the article's Creative Commons license, unless indicated otherwise in a credit line to the material. If material is not included in the article's Creative Commons license and your intended use is not permitted by statutory regulation or exceeds the permitted use, you will need to obtain permission directly from the copyright holder. To view a copy of this license, visit http://creativecommons. org/licenses/by/4.0/.

(c) The Author(s) 2019 